\title{
Gestão social e desenvolvimento comunitário: o poder da organização informal em empreendimentos habitacionais de interesse social
}

\author{
Suzana Melissa de Moura Mafra da Silva ${ }^{1}$ \\ WASHINGTON JOSÉ DE SOUZA ${ }^{1}$ \\ ${ }^{1}$ Universidade Federal do Rio Grande do Norte (UFRn) / Programa de Pós-Graduação em Administração, Natal - RN, Brasil
}

\begin{abstract}
Resumo
Este estudo tem como objetivo qualificar o processo de gestão social baseado em atributos de desenvolvimento comunitário revelados pelo trabalho social realizado por um grupo informal de beneficiários de um empreendimento financiado pelo Sistema Nacional de Habitação de Interesse Social, localizado no município de São Gonçalo do Amarante (RN). A pesquisa se concentra no caso de um coletivo local informalmente constituído sob a denominação de Associação Lambe Sal. A análise lexicométrica dos dados coletados, por meio do grupo focal com membros desse coletivo, evidencia que o envolvimento da comunidade tem funções relevantes no empreendimento, revelando uma prática de gestão social caracterizada pela interdependência e baseada em princípios solidários que contribuem para a solidariedade e une as pessoas pelo trabalho voluntário, vinculando-as por serviços como limpar áreas comuns e promover eventos de lazer. A qualidade do diálogo e das relações intersubjetivas contribuem para apontar iniciativas emancipatórias e revelar melhorias na vida comunitária, que excedem as funções e os interesses originários do grupo.
\end{abstract}

Palavras-chave: Gestão social. Organização informal. Desenvolvimento comunitário. Organização comunitária. Habitação de interesse social.

Social management and community development: the power of informal organization in social interest housing projects

\begin{abstract}
This study aims to qualify a social management process based on community development attributes revealed in social work carried out by an informal group of beneficiaries of a venture financed by the National Social Interest Housing System, located in the municipality of São Gonçalo do Amarante (RN). The research focuses on the case of a local informal collective called Lambe Sal Association. The lexicometric analysis of the data collected via a focus' group with members of the association shows that the community's engagement has relevant functions in the venture. This reveals a social management practice characterized by interdependence and solidary principles that contribute to solidarity, bringing people together through volunteering, linking them through services such as cleaning common areas, and promoting leisure events. The quality of the dialogue and intersubjective relations contribute to point out emancipatory initiatives and reveal communitarian life improvements that exceed the original functions and interests of the group.
\end{abstract}

Keywords: Social management. Informal organization. Community development. Community organization. Social interest housing.

Gestión social y desarrollo comunitario: el poder de la organización informal en proyectos de viviendas de interés social

\section{Resumen}

Este estudio tiene como objetivo calificar el proceso de gestión social a partir de los atributos de desarrollo comunitario presentes en el trabajo social realizado por un grupo informal compuesto por beneficiarios de un emprendimiento financiado por el Sistema Nacional de Habitación de Interés Social. La investigación se centra en el caso de un colectivo local constituido informalmente bajo el nombre de Asociación Lambe Sal. El análisis lexicométrico de los datos recopilados -a través de un grupo focal de miembros de dicho colectivo- evidencia que la participación de la comunidad cumple funciones relevantes en el emprendimiento, lo que revela una práctica de gestión social caracterizada por la interdependencia y fundamentada en principios que contribuyen a la solidaridad y unen a las personas por el trabajo voluntario, vinculándolas por medio de faenas tales como limpiar áreas comunes y promover eventos de ocio. La calidad del diálogo y de las relaciones intersubjetivas contribuye a señalar iniciativas emancipadoras y revelar mejoras en la vida comunitaria que exceden las funciones y los intereses originales del grupo.

Palabras clave: Gestión social. Organización informal. Desarrollo comunitario. Organización comunitaria. Habitación de interés social. 


\section{INTRODUÇÃO}

Estudos de programas habitacionais brasileiros vinculam déficits de unidades habitacionais a uma estrutura geradora e reprodutora de desigualdades socioespaciais, de tal modo que a habitação de interesse social ainda não se constitui no país como política contínua (Valadares \& Cunha, 2018). As diferentes configurações de programas de habitação e a reprodução de padrões de protagonismo do setor empresarial e segregação socioespacial das cidades (Balbim \& Krause, 2014; Bonduki, 2009; Cardoso \& Aragão, 2013; Fix \& Arantes, 2009; Grazia \& Melo, 2017; Nisida, Vannuchi, Rossi, Borrelli \& Lopes, 2015) motivaram movimentos sociais e entidades da sociedade civil a exigir dos agentes governamentais o exercício do controle social (Valadares \& Cunha, 2018) e o ideal de cidades justas e sustentáveis (Grazia \& Melo, 2017). Demandas dessa natureza explicam a iniciativa de incorporação de instrumentos de participação e controle na gestão de empreendimentos habitacionais de interesse social, consubstanciados no formato de Projeto de Trabalho Técnico Social (PTTS). Compete à Caixa Econômica Federal (CEF), na qualidade de agente operador do Fundo Nacional de Habitação de Interesse Social (FNHIS), nos termos do art. 16, da Lei no 11.124, de 16 de junho de 2005, definir e implementar os procedimentos operacionais necessários à aplicação dos recursos do FNHIS.

Na operacionalização do FNHIS, a CEF, no Caderno de Orientação Técnico Social (COTS) (CEF, 2013), trata de bases para elaboração, implantação e avaliação de PTTS, assinalando o propósito de fomentar a participação da comunidade e assegurar que a sociedade, em especial as famílias diretamente beneficiadas, se envolva na gestão social das demandas comunitárias. A CEF (2013) prevê participação dos beneficiários desde a fase de concepção do PTTS, durante o período de obras, até a etapa posterior à conclusão das obras e entrega dos imóveis, ou seja, na pós-ocupação. O PTTS, no COTS (CEF, 2013), exige equipe de profissionais com formação especializada, dimensionada de acordo com o volume e os recursos disponíveis, podendo ser efetivado tanto pelo agente público tomador do empréstimo quanto por terceiros.

O PTTS tem adquirido "conteúdos diferenciados conforme as conjunturas históricas que atravessaram as políticas urbanas e habitacionais desde os anos 1950, que, de conservadoras, sanitaristas e assistencialistas, passaram a ser concepções que contribuem para a construção da cidadania" (Grazia \& Melo, 2017, pp. 353-354). É válido acatar que o trabalho social em empreendimentos habitacionais traz contribuições à construção de cidadania além de laços de proximidade e confiança entre os moradores. É igualmente válido, todavia, questionar a qualidade do conteúdo e dos resultados, assim como a forma como são conduzidas as ações de trabalho social em empreendimentos habitacionais, o que é objeto do presente texto.

Nosso percurso se exime de análise de PTTS considerando que a experiência narrada é justamente um contraponto às ações financiadas pela prefeitura de São Gonçalo do Amarante (RN), no Residencial Ruy Pereira dos Santos, empreendimento construído no âmbito do Programa Minha Casa, Minha Vida, com 1.800 unidades habitacionais no total. De todo modo, a referência ao PTTS se torna pertinente como contraponto analítico, uma vez que se trata do único instrumento governamental destinado a orientar o desenvolvimento comunitário em empreendimentos habitacionais de interesse social. Podemos nos referir, porém, a um "PTTS informal", concebido e implementado por comunitários na fase pós-ocupação.

Adotamos o objetivo de qualificar processos de gestão social com base em atributos de desenvolvimento comunitário presentes em trabalho social efetivado por grupo informal constituído por beneficiários de empreendimento financiado pelo Sistema Nacional de Habitação de Interesse Social (SNHIS) (Lei no 11.124, de 16 de junho de 2005). A questão central é: como ações de trabalho social, autonomamente concebidas e executadas por comunitários em empreendimento habitacional de interesse social, se conciliam em categorias analíticas validando processos de gestão social?

O Residencial Ruy Pereira dos Santos é um empreendimento localizado no município de São Gonçalo do Amarante (RN). A pesquisa assume relevância por revelar fragilidades de projetos de interesse público que, uma vez forjados por equipe técnica especializada com propósitos de fomentar desenvolvimento comunitário, limita o alcance e a qualidade dos resultados pretendidos. De outra forma, conforme reportou Silva (2017) em tese realizada no curso de doutorado em administração da Universidade Federal da Bahia (UFBA), a extensão universitária, sob viés de desenvolvimento territorial ancorado em processos de gestão social, contribui para qualificar o trabalho social em empreendimentos habitacionais de interesse social. Por essa razão, entendemos que o presente texto, do mesmo modo que o supracitado autor, traz contribuições aos estudos organizacionais e ao universo da prática acadêmica. 
Considerando que mobilização e organização comunitárias, educação ambiental e geração de trabalho e renda são eixos estruturantes do PTTS (CEF, 2013), a pesquisa assume a premissa de que referenciais de gestão social são úteis para explicar fracassos do poder público no trabalho social em contraposição a sucessos da auto-organização de comunitários. Tomamos como base a participação social, especificamente para fazer referência à Constituição Federal de 1988 e, por derivação, ao conceito de cidadania deliberativa de Jürgen Habermas, introduzido no Brasil por Tenório (1998), conforme pontuam Salgado, Santos, Resende e Souza (2019). Assim, o tópico seguinte aborda tais conceitos com o propósito de extrair atributos de gestão social para interpretação dos resultados da pesquisa de campo, cujos procedimentos metodológicos se encontram no tópico subsequente. $O$ texto tem sequência com a discussão dos resultados com base nas interlocuções entre atributos teóricos de gestão social selecionados e categorias empíricas geradas pelo software gratuito de análise de dados Iramuteq. Encerra o texto a Conclusão, destinada à indicação de lacunas e estudos futuros no tema e à síntese de contribuições da pesquisa na retroalimentação do trabalho social em empreendimentos habitacionais de interesse social.

\section{A NATUREZA INTERACIONAL DA GESTÃO SOCIAL}

Peres e Pereira (2014) realizaram levantamento bibliométrico dos usos frequentes da gestão social no Brasil revelando que, em todas as abordagens, o sociólogo português Boaventura de Sousa Santos é citado, em especial, pela obra Democratizar a democracia: os caminhos da democracia participativa (2002). Os autores concluem pela proeminência de conceitos como participação, diálogo e busca do bem comum na delimitação de uma concepção nacional de gestão social. Eles apontam duas vertentes de aplicação: uma vinculada à gestão pública, sob a noção de administração pública societal, gestão do desenvolvimento social ou gestão do social, e outra vinculada à ação gerencial dialógica, utilizada em diferentes sistemas sociais privados, não governamentais e públicos.

Em exercício teórico, igualmente de sistematização, Cançado, Pereira e Tenório (2015) elencam as seguintes categorias para a gestão social: democracia deliberativa, dialogicidade, emancipação, esfera pública, interesse bem compreendido, intersubjetividade, racionalidade, solidariedade e sustentabilidade. Com tais categorias, os autores estabelecem um quadro de análise com a seguinte configuração: a) interesse bem compreendido (IBC), abrigando as categorias solidariedade e sustentabilidade; b) esfera pública, como locus e condição essencial para a gestão social, abrigando as categorias democracia deliberativa, dialogicidade, intersubjetividade e racionalidade; c) emancipação, como ponto de chegada. O raciocínio dos autores está disponível no texto supracitado, dispensando aqui explanações complementares.

Interessa ao nosso exercício, baseado em tais referências, reforçar o caráter interacional da gestão social. Tal interesse é bem compreendido, por exemplo, na leitura de Tocqueville (1998), que, conforme pontuam Cançado et al. (2015), assume a premissa de que bem-estar coletivo é precondição para proporcionar bem-estar individual. Refere-se a uma virtude útil a partir da qual, ao defender interesses coletivos, o indivíduo defende os próprios interesses. Essa noção conduz os referidos autores a relacionar, no IBC, as categorias solidariedade e sustentabilidade, que, em essência, apresentam propósitos compartilhados por grupos e sociedades. O IBC imprime noção de interdependência, quando indivíduos percebem a dinâmica da atuação própria na esfera pública, sob o viés da (re)construção coletiva do lugar, com a intenção de contribuir para o bem-estar coletivo e, por conseguinte, para o bem-estar individual (Cançado et al., 2015). São, assim, ocasiões nas quais indivíduos percebem que dependem uns dos outros, afastando sentimentos egocêntricos e de independência que confundem liberdade com autossuficiência privada.

Cançado et al. (2015) elegem as categorias democracia deliberativa, dialogicidade, intersubjetividade e racionalidade na delimitação de características atinentes ao processo de tomada de decisão à luz da gestão social. A democracia deliberativa assume "[...] a forma de tomada de decisão dentro desta esfera pública na qual acontece a Gestão Social, porém, são necessárias outras categorias teóricas para a construção de seu escopo" (Cançado et al., 2015, p. 10). Com viés similar, Oliveira, Cançado e Pereira (2010, p. 624) desenham aproximações entre os espaços participativos e a gestão social, compreendendo que "a esfera pública brasileira tem (re)criado espaços públicos, onde a ação pública se torna possível”, de modo que a gestão social se torna possibilidade para tais espaços, pois o que neles se busca é a efetividade da coletividade na decisão.

Decisões na esfera pública, do ponto de vista da gestão social, abarcam, além do critério da democracia deliberativa, dialogicidade, entendida como "a capacidade de se comunicar e, por consequência, se entender com outras pessoas", bem como intersubjetividade, materializada na "capacidade dos indivíduos de entender a subjetividade do outro por meio da 
comunicação [...] e do conhecimento da língua e dos símbolos utilizados para a comunicação que acontece, na percepção, também, do 'não dito'”. O outro componente, caracterizador da natureza das decisões tomadas na esfera públicas, é a racionalidade, nesse caso fundamentada na ação racional substantiva, ou seja, num "equilíbrio entre satisfação social e satisfação pessoal que promove o desejo da capacidade humana de autorrealização, autodesenvolvimento e emancipação" (Cançado et al., 2015, p. 12).

Emancipação, como ponto de chegada dos processos de gestão social, representa "[...] libertação de uma dominação opressora, baseada nas relações de produção e reprodução da vida, tornando-se processo de ruptura com a subalternidade e recusa à manipulação" (Cançado et al., 2015, p. 12). Podemos resumir, portanto, que, como processo de tomada de decisão, a gestão social:

1) Tem início numa necessidade: o IBC, quando indivíduos assumem a intenção de contribuir para o bem-estar coletivo entendendo que, por esse caminho, alcançam o bem-estar próprio. Esse requisito prévio não aparece na súmula da sistematização, acima referida, de Peres e Pereira (2014). Todavia, é componente relevante ao processo de gestão social, por nós considerado adiante na discussão dos resultados da pesquisa de campo.

2) Ocorre na esfera pública, em processos de democracia deliberativa (Cançado et al., 2015), ou, em sentido similar, no encontro de indivíduos em dado lugar com propósitos de, por meio de processos de tomada de decisão participativo e dialogado (Peres \& Pereira, 2014), alcançar o bem comum.

3) Objetiva emancipação (Cançado et al., 2015), em outras palavras, bem comum (Peres \& Pereira, 2014).

Temos, então, que duas revisões no conceito e na categorização de elementos da gestão social no Brasil, ocorridas em 2014 e 2015, respectivamente, se alinham ao entendimento de Fischer et al. (2006), esboçado na década imediatamente anterior. Podemos sintetizar que a gestão social é "reflexo das práticas" - originárias de processos participativos e experimentações empíricas de democracia deliberativa - e "do conhecimento construído por múltiplas disciplinas" - o que lhe imprime uma natureza teórica -, "delineando-se uma proposta multiparadigmática, de natureza interdisciplinar" (Fischer et al., 2006, p. 797). A integração teoria-prática, de Fischer et al. (2006), é nítida nas duas revisões supracitadas. Peres e Pereira (2014) identificam participação e dialogicidade como elementos inerentes a processos de gestão social, em práticas de busca pelo bem comum. Em sentido similar, Cançado et al. (2015) elegem dimensões de IBC e de esfera pública como princípio e meio de processos de gestão social, respectivamente, entendendo que a finalidade é a emancipação.

Igualmente em exercício de sistematização, Salgado et al. (2019) reiteram a compreensão interacional com base na análise do emprego do construto cidadania deliberativa, de Jürgen Habermas, na gestão social no Brasil. Eles resumem que "o campo de conhecimento da gestão social aparece, nos artigos analisados [18 no total], fundamentado em três grandes categorias articuladas entre si: interesse público (ou seja, Interesse Bem Compreendido), esfera pública e emancipação social" (Salgado et al., 2019, p. 825). Desse modo, podemos tomar o modelo de Cançado et al. (2015) para análise empírica do objeto aqui pautado: desenvolvimento comunitário em empreendimento habitacional de interesse social.

\section{PROCEDIMENTO METODOLÓGICO}

A estratégia metodológica assumida segue para qualificar processo de gestão social com base em atributos de desenvolvimento comunitário extraídos do trabalho social realizado por um grupo de moradores do Residencial Ruy Pereira dos Santos, na forma de associação informal constituída, exclusivamente, por homens. O residencial agrupa seis condomínios com dezoito blocos de dezesseis apartamentos, além de um bloco com mais doze apartamentos, totalizando trezentas moradias por condomínio. Com população estimada superior a 7.200 habitantes, o empreendimento está localizado no município de São Gonçalo do Amarante (RN).

Dos seis condomínios, o Condomínio Ruy Pereira I (CRP-I) foi selecionado para a coleta dos dados, a princípio com o propósito de avaliar resultados do PTTS contratado pela prefeitura. O CRP-I foi selecionado tanto pelo fato de ter sido ocupado primeiro e, portanto, ter recebido o maior volume de ações do PTTS efetivado por uma empresa contratada por licitação pública quanto pela acessibilidade, manifestada na disponibilidade do síndico para contribuir com a equipe da pesquisa e operacionalizar as 
reuniões demandadas para a coleta dos dados. Durante a primeira reunião para a coleta de dados via grupo focal e entrevista semiestruturada com moradores do condomínio, a equipe tomou conhecimento das ações realizadas pela Associação Lambe Sal no CRP-I. Para os presentes, a Lambe Sal apresentava resultados superiores, em termos de efetividade e de envolvimento quantitativo dos moradores, àqueles imputados ao PTTS da prefeitura. Diante da unanimidade em torno de tal entendimento, a equipe decidiu tomar, como unidade de análise, a Lambe Sal, para a realização de grupo focal, com coleta de informações complementares, via entrevista semiestruturada com os síndicos.

Frente ao objetivo proposto, optamos por uma perspectiva que integra abordagens quantitativa e qualitativa. O estudo é do tipo descritivo, com viés teórico-empírico. Trata-se ainda de estudo de caso, com percurso metodológico iniciado em pesquisa bibliográfica, seguida pela pesquisa de campo no Residencial Ruy Pereira dos Santos. Foram realizadas três visitas ao residencial, especificamente aos condomínios I e VI, ambos com ocupação concluída. Foi realizada entrevista semiestruturada (Flick, 2009) com os respectivos síndico e subsíndico, a fim de reforçar entendimentos em torno dos desafios enfrentados pelos moradores no lugar na fase pós-ocupação. Após o contato com os síndicos, que forneceram um panorama geral acerca dos desafios enfrentados, ocorreram s referências à Associação Lambe Sal, um coletivo de cerca de cinquenta homens do CRP-I. Trata-se de grupo informal concebido em horas de lazer e que, aos poucos, passou a assumir funções organizativas estruturantes de natureza comunitária, com ações acessórias àqueles da associação condominial.

Após o contato com o líder da associação em pauta, foi procedida uma sessão de grupo focal, instrumento escolhido por permitir flexibilidade na interação entre os moradores em discussão grupal (Flick, 2009). Do grupo focal participaram doze homens, com faixa etária entre 27 e 55 anos - com média de 40 anos -, renda máxima de três salários-mínimos, em trabalhos de vigilante, pedreiro, auxiliar de manutenção, serviços gerais, garçom e vendedor, com ensino fundamental e médio, sem registro de ensino superior. Um participante indicou estar aposentado por invalidez e, outro, desempregado. A denominação do coletivo tem origem em brincadeiras entre os membros para fazer referência a homem traído, fato que explica a presença exclusiva de homens. Tal alusão, explicaram, deve-se ao fato de que o animal bovino costuma lamber sal.

O grupo focal ocorreu mediante roteiro semiestruturado com questões ordenadas em quatro blocos, versando sobre perfil dos moradores, cotidiano e desafios enfrentados e medidas adotadas. A coleta foi centrada no propósito de qualificar o processo de gestão social no desenvolvimento comunitário pela atuação da Lambe Sal no CRP-I. À época, a associação de moradores se encontrava em constituição e dois condomínios - seiscentas unidades habitacionais - não haviam sido ocupados.

As orientações de condução de grupo focal de Flick (2009) foram seguidas, e, assim, a coleta contou com mediador, moderador assistente e um auxiliar, responsável pela condução do debate, por tomar nota de percepções e realizar registros audiovisuais. Além disso, previamente foi requerida a concordância individual dos presentes por meio da assinatura de termo de consentimento livre e esclarecido (TCLE). Os doze membros da Lambe Sal que participaram do grupo focal estão adiante identificados em códigos de A1 a A12.

A entrevista semiestruturada, por sua vez, teve propósito de esclarecimento e confirmação de informações e dados coletados no grupo focal. A escolha por essa tipologia de entrevista reside na "expectativa de que é mais provável que os pontos de vista dos sujeitos entrevistados sejam expressos em uma situação de entrevista com um planejamento aberto do que em uma entrevista padronizada ou em um questionário" (Flick, 2009, p. 143). Conforme já enunciado, foram selecionados o síndico e o subsíndico dos dois condomínios que haviam concluído o processo de pós-ocupação (CRP-I e CRP-V). As questões nesse caso seguiram os mesmos blocos do grupo focal.

Os dados foram transcritos e, posteriormente, analisados com base na abordagem lexicométrica, apoiada pelo software gratuito de análise de dados Iramuteq, que utiliza cálculos estatísticos para realizar análises a respeito de corpus textuais e tabelas indivíduos/palavras (Camargo \& Justo, 2013). O software viabiliza a aplicação de procedimentos simples e de análises multivariadas, entre as quais se encontra a classificação hierárquica descendente (CHD). Nesta pesquisa, foi utilizada a CHD para operacionalizar os dados obtidos no grupo focal, considerando que a aplicação da entrevista semiestruturada teve caráter exclusivamente confirmatório, não demandando informações adicionais. Com base no processamento do texto transcrito, em corpus unificado, o software gerou classes analíticas e dados estatísticos que dão suporte à discussão dos resultados na sequência narrada. 


\section{INTERLOCUÇÕES ENTRE CATEGORIAS DE GESTÃO SOCIAL E PRÁTICAS LOCAIS DE DESENVOLVIMENTO COMUNITÁRIO}

Na dissertação Para uma gestão social no Programa Minha Casa, Minha Vida: reflexões acerca da organização comunitária na faixa 1, Cardoso (2015) empregou o modelo teórico aqui referido, de Cançado et al. (2015), na análise de duas experiências de trabalho social. Num dos empreendimentos estudados, foi realizado PTTS pela prefeitura de Assú (RN). No outro, em São Gonçalo do Amarante, não houve PTTS, mas havia uma associação comunitária funcionando e que foi escolhida como lócus da pesquisa. $\mathrm{Na}$ análise dos dois casos, Cardoso (2015) explorou externalidades de organização comunitária com base em formalidades, empregando, como lente teórica, o supracitado modelo teórico (Cançado et al., 2015) e as orientações do PTTS, de acordo com instrumento da CEF. Em um caso, o autor pautou a implementação de PTTS pela prefeitura de Assú; no outro, a utilidade da Associação de Moradores do Conjunto Brasil em São Gonçalo do Amarante.

O caso aqui abordado, ao contrário de Cardoso (2015), traz externalidades de gestão social derivadas de ações de desenvolvimento comunitário, baseado na atuação de um grupo informal de moradores autodenominado Associação Lambe Sal. Sem qualquer registro, a associação é formada exclusivamente por homens, cuja origem remonta a relações de moradores em horas de lazer. Surgiu de brincadeiras entre homens que, em fins de semana, se encontravam em frente ao condomínio para conversas e brincadeiras. O coletivo tem origem genuinamente comunitária, sem qualquer participação de agente externo. 0 grupo assumiu o objetivo de organizar passeios e festas para integrar as famílias dos moradores e convidados eventuais. São cerca de cinquenta homens (famílias) associados que, com identidade de associação - ainda que informal -, detém uma direção nas figuras de presidente, vice-presidente e tesoureiro, escolhidos pelos demais participantes para o exercício de suas funções.

Figura1

Parte dos integrantes do coletivo Lambe Sal

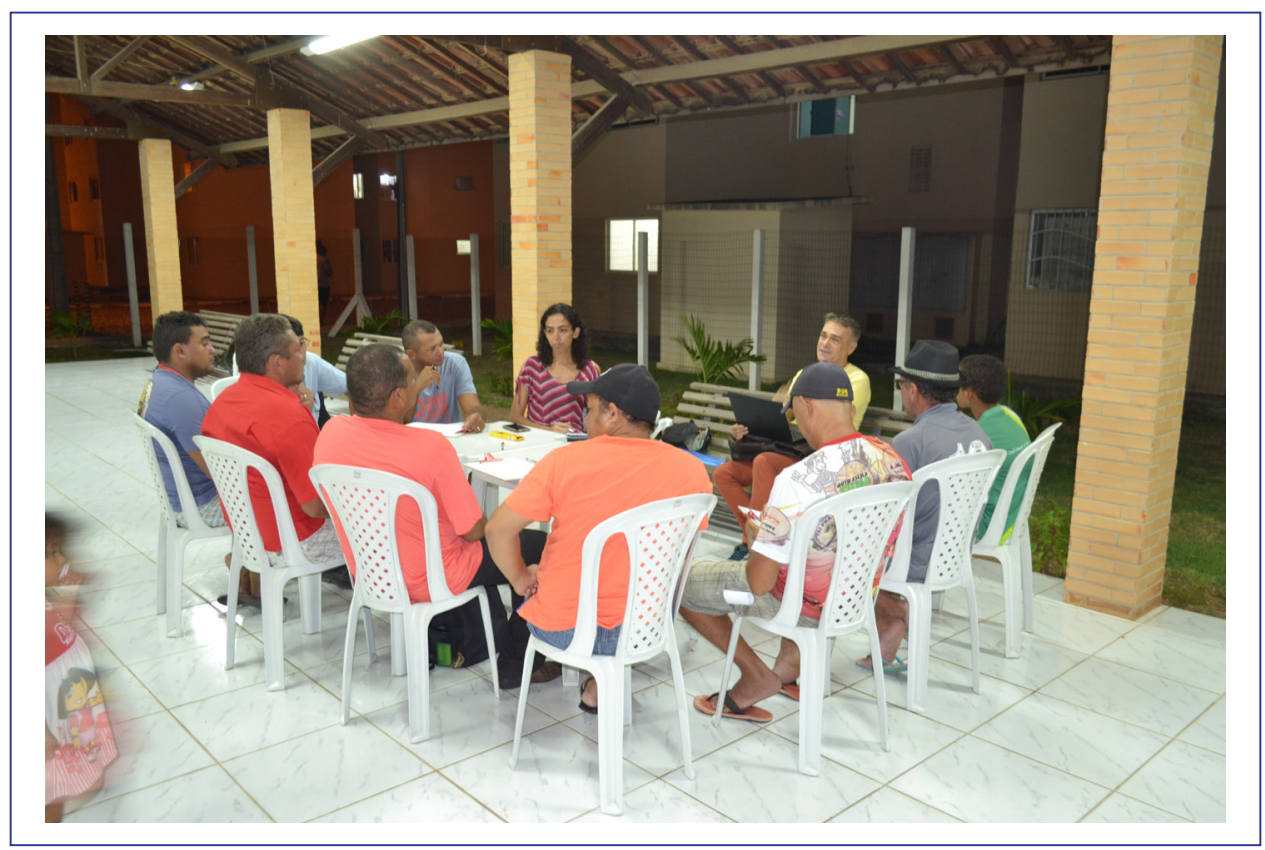

Fonte: Acervo dos autores (2020).

A associação tem como política a cobrança de taxa mensal simbólica, no valor de $\mathrm{R} \$$, para atividades recreativas entre as famílias dos sócios. Todavia, reiterados atrasos nos pagamentos da taxa condominial têm levado a Lambe Sal a compartilhar parte dos recursos do coletivo com o todo, incluindo despesas com limpeza e manutenção das áreas comuns. Além dessa ação voluntária, o coletivo assume festas em datas comemorativas, com participação aberta, e quita pequenas despesas de interesse geral. 
Com a transcrição do grupo focal foi elaborado um corpus cujo processamento do Iramuteq vem acompanhado de estatística. No corpus, o software identificou 268 segmentos de texto (ST), correspondentes aos cortes que a ferramenta faz a cada conjunto de quarenta palavras. O aproveitamento foi de 192 ST, representando $71,64 \%$ de retenção, porcentagem considerada suficiente para garantir qualidade aos achados (Camargo \& Justo, 2016). Foram contabilizadas 8.845 ocorrências (palavras, formas ou vocábulos), sendo 1.403 palavras distintas e 671 com ocorrência única.

A classificação hierárquica descendente (CHD) do Iramuteq gerou quatro classes: 1, com 53 ST (27,6\%); 2, com 35 ST (18,23\%); 3, com 45 ST (23,44\%); e 4, com 59 ST (30,73\%). Esses dados estão no dendrograma (Figura 2) que também resume palavras significativas, cuja ordenação se dá por meio do teste qui-quadrado $\left(\mathrm{x}^{2}\right)$ para indicar a força de associação de cada palavra à classe. As classes receberam denominação, a posteriori, com base no conjunto de palavras de cada agrupamento.

Figura 2

Dendrograma das classes com algumas palavras caracterizadoras

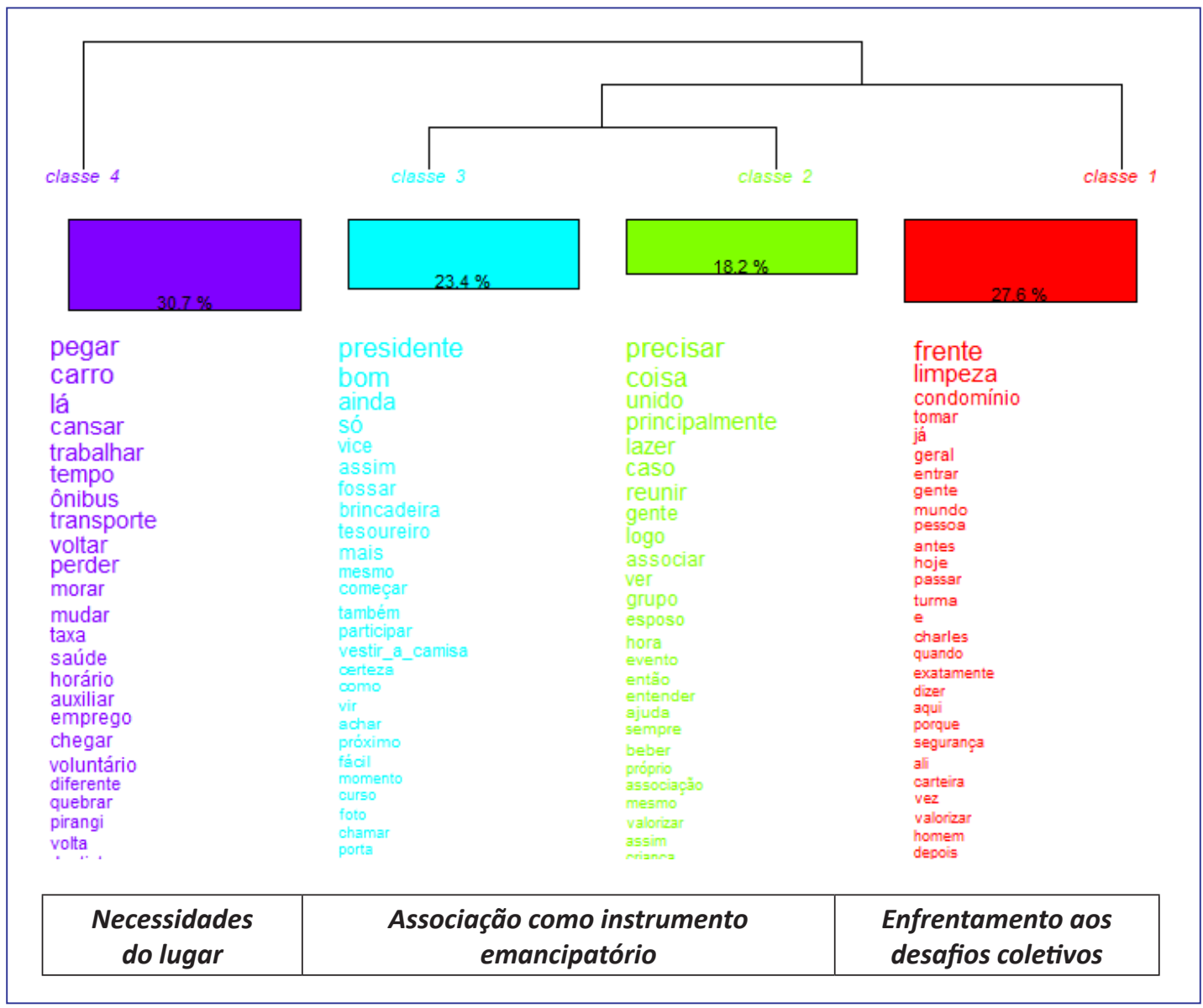

Fonte: Adaptada do software Iramuteq. Dados da pesquisa (2020).

Considerando a característica hierárquica da classificação apresentada no dendrograma, as classes temáticas são analisadas seguindo a ordem de independência em relação às demais, de modo que a sequência de análise deve respeitar a seguinte ordem no caso em pauta: necessidades do lugar (classe 4), enfrentamento aos desafios coletivos (classe 1) e associação como instrumento emancipatório (classes 2 e 3).

A classe 4, que denominamos "Necessidades do lugar", diz respeito a evocações relacionadas a carências na infraestrutura local, no entorno do residencial, a começar pela localização, distante cerca de 4,5 km do centro administrativo de São Gonçalo do Amarante e cerca de 3,2 km do distrito de Santo Antônio, pertencente ao município. A Figura 3 ilustra a localização do residencial em relação aos dois pontos referidos e às principais vias de acesso. 
Figura 3

Residencial Ruy Pereira em relação ao município de São Gonçalo do Amarante, ao distrito de Santo Antônio do Potengi e às principais estradas de ligação

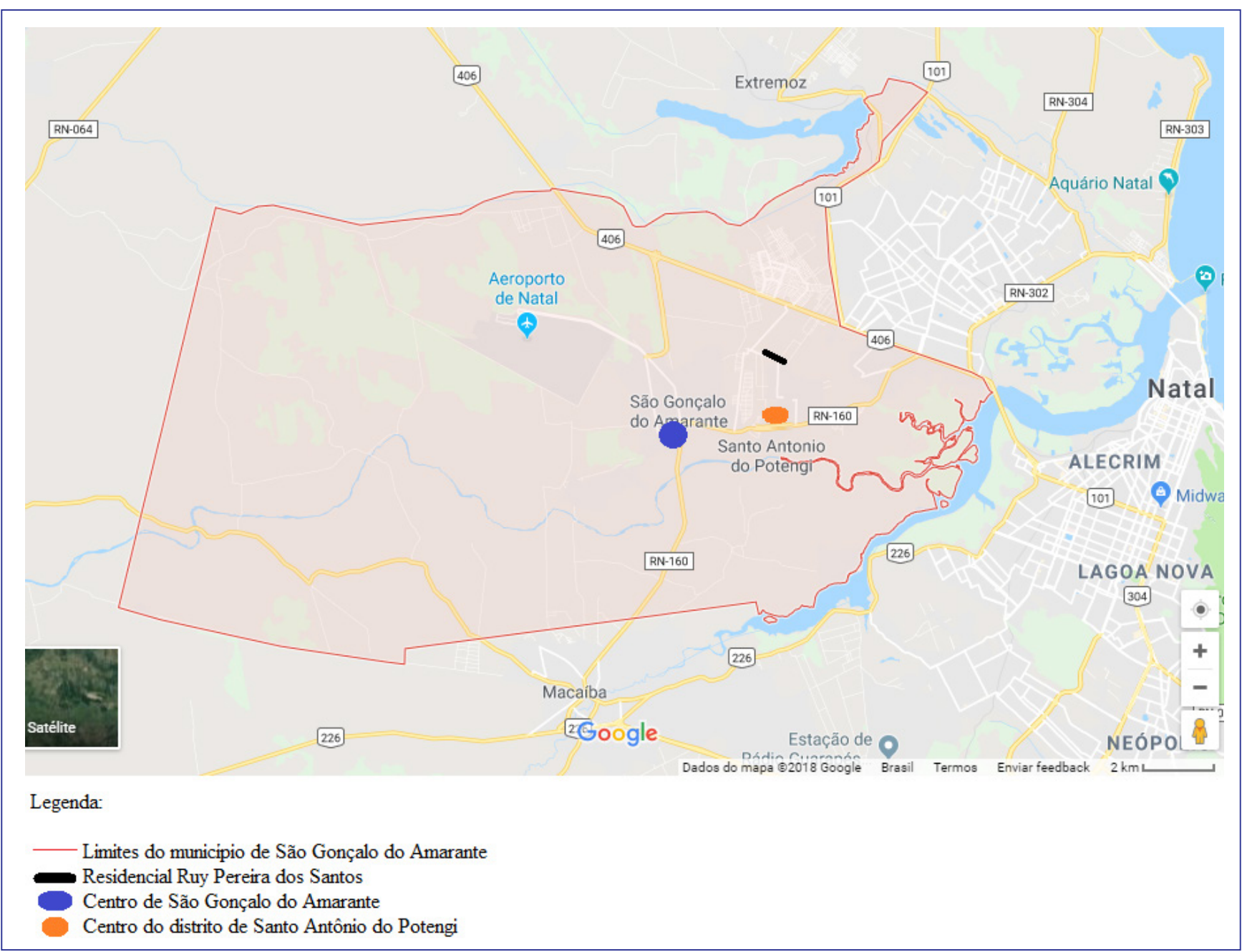

Fonte: Adaptada do Google Maps (2020).

Destaque é dado ao transporte urbano, mencionado com recorrência, por ser o único meio de locomoção de parte significativa dos moradores, inclusive no traslado para o trabalho. Um dos participantes informou ter perdido o emprego em virtude de irregularidades sistemáticas no serviço do transporte público local. "Cansar", "ônibus", "carro", "transporte", "pegar" e "perder" ilustram fortemente o fenômeno. A análise de similitude do Iramuteq, baseada na teoria dos grafos, reforça a relação de "pegar", principalmente, a "chegar" e "trabalhar". llustram esse fenômeno evocações como "tem que pegar 2 ônibus pra chegar aqui" (A5), "pego um circular aqui, pego o R [...] depois pego o [ônibus]10. Chego lá cansado, canso mais da viagem de ônibus do que no trabalho" (A1). "Chegar", por sua vez, remete a algum dos destinos do trajeto casa-trabalhocasa. A relação com a qualidade de vida é observada pela presença do vocábulo "saúde" em posição mais inferior na classe. 
Figura 4

Análise de similitude do vocábulo pegar

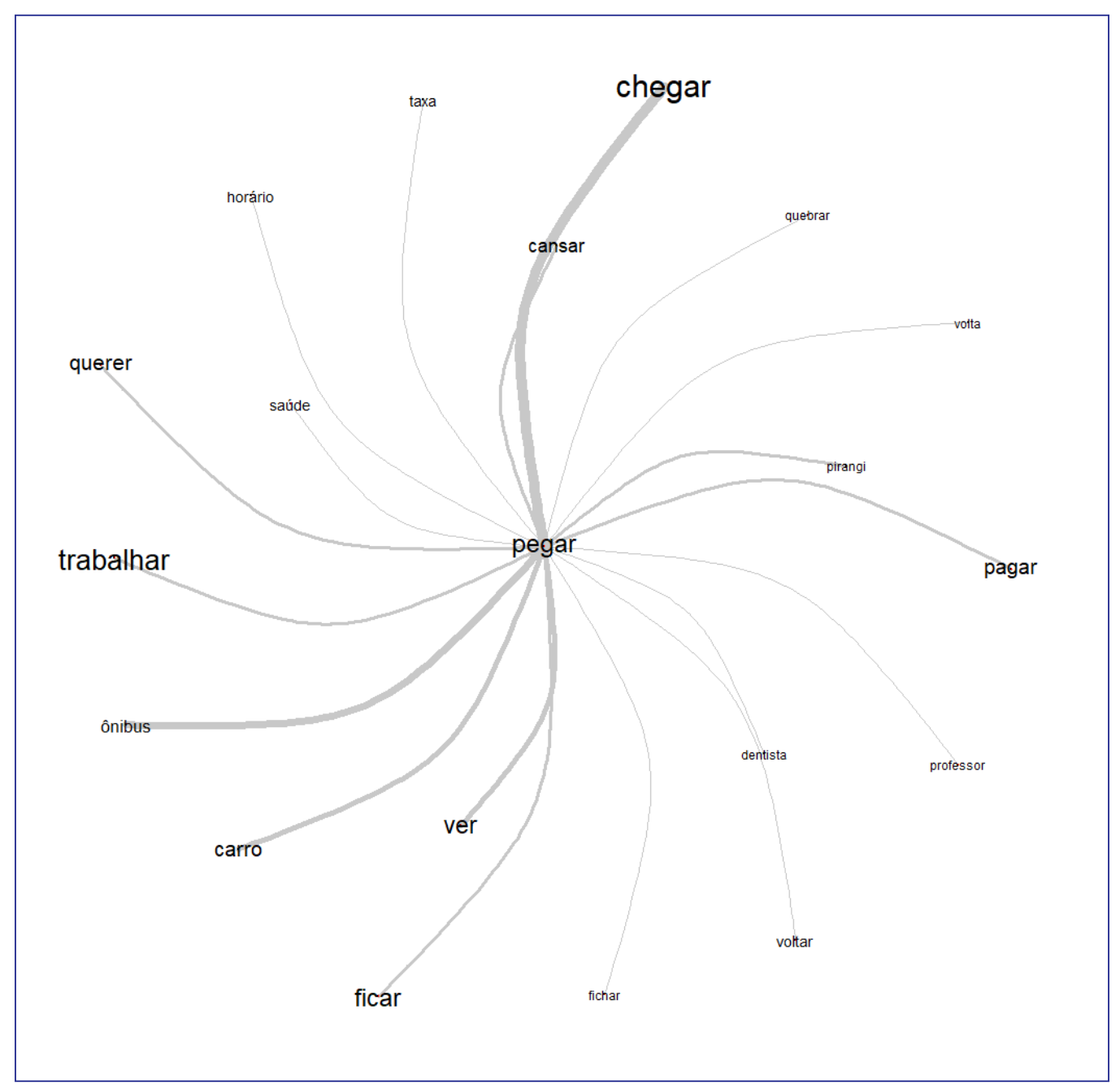

Fonte: Adaptada do software Iramuteq. Dados da pesquisa (2020).

Pelo fato de a Lambe Sal não alcançar a totalidade das famílias - tem cinquenta associadas num universo de trezentos no CRP-I -, não é possível relacionar estabilidade nas relações sociais e identidade com o lugar pela sua atuação. É fato, todavia, que o coletivo tem identidade internamente e com o lugar, gerando proximidade e solidariedade que extrapolam interesses exclusivos dos associados. É interessante observar que a associação, de acordo com os participantes, foi constituída com o propósito de lazer, para aproximar as famílias. Todavia, a permanência dos membros ultrapassa essa motivação: "[...] porque digo a você: se não fosse nós, hoje, nós da associação, que a gente começou [as atividades de limpeza] antes de fazer a associação, não sei como seria a limpeza do condomínio" (A2). A ideia é reforçada pela perspectiva de racionalidade substantiva apontada pelo Morador A7: "A gente tá no grupo porque a gente fica ajudando um ao outro a fazer uma coisa, a fazer outra, assim [...] aí no caso, se a gente [...] no caso, eu saio, ele aqui sai [...] já vai fazer falta, já vai desmanchando."

O trabalho social orientado para a coletividade se aproxima da categoria "interesse bem compreendido" (Cançado et al., 2015), tomada como precondição para o bem-estar individual, o que, nas falas dos moradores associados, remete a ações que compartilham no ambiente físico: "Quando vou fazer a limpeza, eu penso [...] nos filhos, quem vai chegar da minha família [...] quem vai entrar [...] Acho que todo mundo tem esse pensamento" (A1); "Isso aqui é como se [...] porque a gente não tem quintal, isso aqui é como se fosse o quintal da nossa casa. O condomínio em si é o quintal da nossa casa. Se a gente não cuidar [...] é como se fosse um lixão, né?" (A2). 
A lógica de interdependência (Cançado et al., 2015) fica evidenciada na percepção dos sujeitos de que atuam na busca de (re)construção do espaço físico - limpeza e pintura de muros - e social, de relações entre os vizinhos - momentos de lazer e eventos em datas comemorativas - e intenções para o bem-estar coletivo. Não estamos, portanto, tratando de relações entre membros de uma associação. Em vez de uma gestão para o interior, no cumprimento da missão que elegeram para o coletivo - lazer para as próprias famílias -, temos uma ação ampliada, que ganha interações não lineares porque destinada a filhos, para quem vai chegar da família e para quem vai entrar no condomínio como visitante.

A classe 1, por sua vez, remete ao enfrentamento aos desafios coletivos, relacionados tanto à busca por qualidade de vida quanto às demandas provenientes da inadimplência no pagamento da taxa condominial, a exemplo da ausência de serviço de limpeza no condomínio. Houve forte menção ao vocábulo "limpeza", visto que é a atividade que mais caracterizava a atuação da associação, conforme relata o Morador A2: "A limpeza do condomínio a gente tá fazendo porque somos uma associação e a gente tá aqui pra fazer isso. E a gente quer o nosso bem." Evocação dessa natureza representa sentimentos do coletivo e aponta para uma natureza da gestão social: a complexidade dos fenômenos públicos não governamentais, de interesse comunitário. Desse modo, a limpeza do condomínio não se resume a faxina e embelezamento, mas também tem o propósito de que "a gente quer o nosso bem". Não ocorreu qualquer manifestação de caráter individual; contrário, os sentimentos externados foram todos de agregação.

O coletivo tem nítida clareza entre o papel que deve assumir (e assume), na contribuição a bem-estar e lazer de associados e agregados, e aquele que é exclusivo da gestão condominial, no tocante à organização comunitária e à condução de problemas, demandas e interesses de toda a comunidade. Mesmo assim, há de considerar que o Lambe Sal contribui para a aproximação das pessoas no CRP-I, tanto pela via do trabalho, quando realiza voluntariamente mutirões de limpeza nas áreas comuns, quanto pelo lazer, quando patrocina festas para as famílias com participação livre. Mas não só. Eles realizam relações híbridas, que saem do ambiente organizacional para o convívio comunitário e exterior, quando demonstram preocupação com familiares e demais visitantes.

O Lambe Sal é uma expressão de gestão da sociedade (Carvalho, 1998) atuando na renovação comunitária por meio de papéis assumidos na política pública habitacional e da adoção de processos flexíveis, não estruturados. Considerando a prática do ponto de vista participativo, sendo o objetivo da participação o compartilhamento de poder entre Estado e sociedade (Dagnino, 2004a, 2004b; Demo, 2009; Presoto \& Westphal, 2005), a experiência do CRP-I é prática incipiente, uma vez restrita a diálogos pontuais com representantes do poder público para a resolução de demandas emergenciais: "Vou ter uma reunião com uma pessoa aí, que eu vou correr atrás dessa pessoa pra no próximo ano ver se ela me ajuda, se ela ajuda a associação, pra ter uma pessoa aqui pra dar aula de reforço. Não sei... Tô esperando a resposta dele, acho que amanhã ele me dá essa resposta" (A2).

Trata-se de compartilhamento de poder que, conforme aponta Demo (2009), tem intervenção na realidade e ocorre por meio de ações orientadas pelo diálogo, numa noção intersubjetiva (Cançado et al., 2015), que é ponto de partida na defesa de interesses da comunidade, com eles contribuindo e estimulando potencialidades. $O$ espaço em que atuam se configura como esfera pública (Habermas, 1997), visto que nele ocorre a validação de normas e ações por meio de decisões coletivas das quais participam atores sociais interessados: "[...] se você chegar e querer fazer parte do grupo, a gente faz a reunião e você vai passar a ser um colaborador" (A3). As expressões enunciadas pelos moradores, ainda que limitadas ao âmbito do condomínio, permitem a aproximação com intersubjetividade e dialogicidade (Tenório, 2005).

$\mathrm{Na}$ análise conjunta das classes 2 e 3, que apresentam a associação como instrumento emancipatório, observam-se evocações vinculadas às relações sociais dos associados no condomínio. Durante a coleta de dados, prevaleceram afirmações integradoras: "somos divertidos, unidos" (A9); "creio aqui que o melhor que tem é a união, embora que esteja aberto [o portão], aqui. É o da gente!" (A5); "é porque não é à toa que o grupo associou quase cinquenta pessoas. Então é um... principalmente o grupo da gente, é um grupo muito unido" (A2). Quando utilizada a funcionalidade concordância na expressão "presidente", destacada na classe 3, fica evidente a relação com falas do presidente da associação, nas quais reforçava o papel de agente mobilizador do coletivo em detrimento de uma concepção autoritária: "Os associados têm que saber que eu não sou a associação, sou apenas presidente, a associação são vocês. A associação só é fraca se vocês enfraquecerem". A mesma compreensão é estendida a outras menções a funções da associação observadas na classe, como vice e tesoureiro. 
Figura 5

Análise de similitude da expressão "presidente"

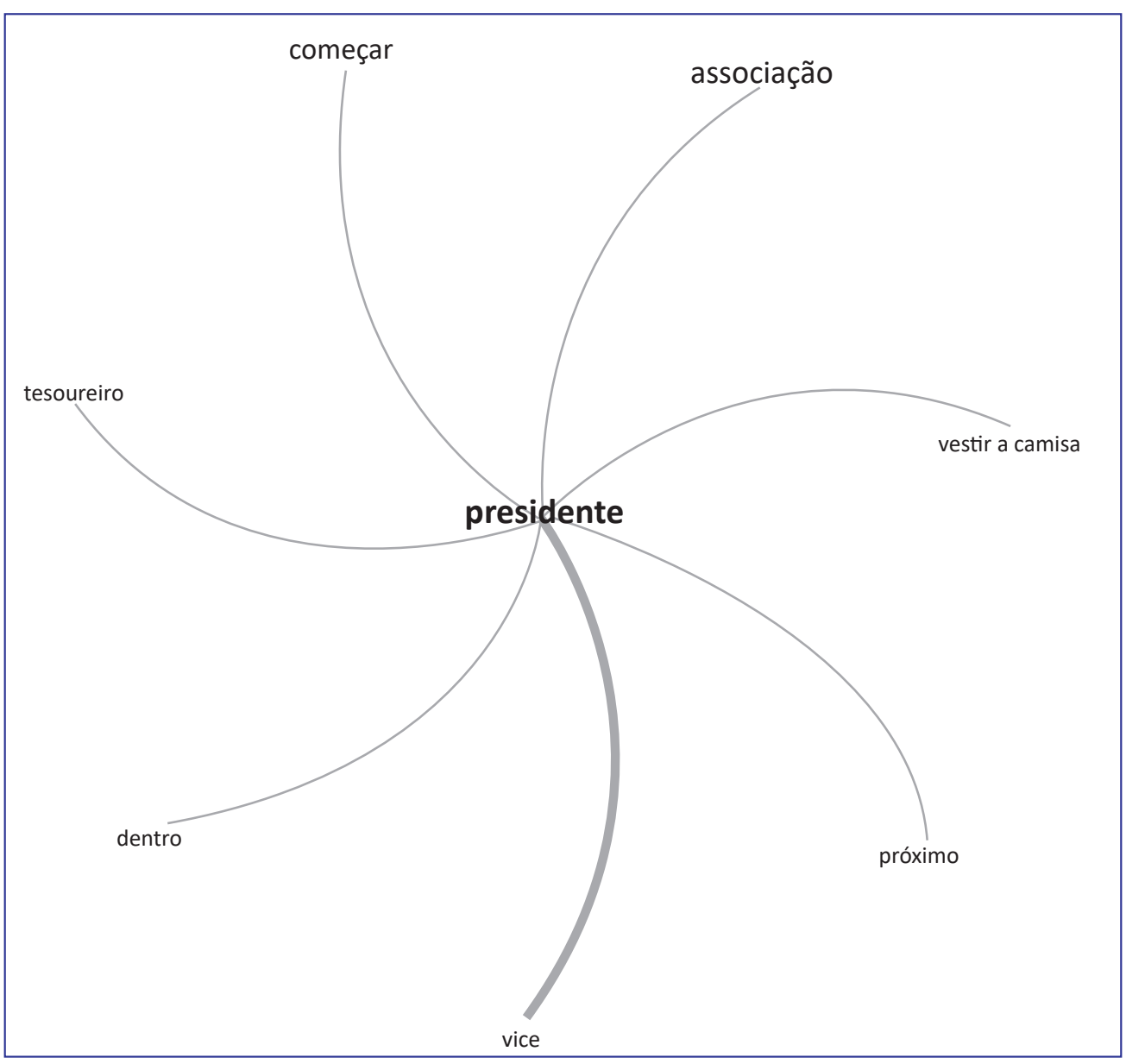

Fonte: Adaptada do software Iramuteq. Dados da pesquisa (2020).

A referência dos moradores à expressão "bom" se associa à avaliação que os moradores realizam da vida comunitária pós-associação. A presença de expressões como "brincadeira" (classe 3), "lazer", "reunir" e "grupo" (classe 2) resgatam os encontros iniciais entre condôminos homens - para conversar e curtir momentos de lazer -, associando aqueles momentos tanto aos motivos da origem quanto às possibilidades de perpetuação da iniciativa. Chama a atenção o fato de que, antes de irem morar no CRP-I, os participantes do grupo não se conheciam, tendo sido pequenas reuniões para diversão momentos que explicam a aproximação e as relações de confiança subsequentes. Os informantes relataram que, a partir do instante que se identificaram como grupo, resolveram nomeá-lo Lambe Sal, em virtude das brincadeiras que faziam para se referir a homem traído: "A gente se reunia aqui e começava a beber, comia um negocinho, aí, [...] uma feijoada [...] era o lazer, né? Assim, começamos a tomar conta do condomínio, em termos de limpar" (A1).

O ideal emancipatório (Cançado et al., 2015) é percebido no modo como o coletivo surgiu e em interesses compartilhados dos associados pela continuidade das ações que desenvolvem, voltadas a propósitos de autonomia "Essa associação vai vingar, sabe? A ideia principal dele tá bem legal” (A7); "Continuidade! Pode até diminuir, mas acabar, eu acho que não acaba, não!" (A1 e A10); "Pra frente, no futuro, nós queremos que seja pra os nossos filhos [...] a gente se esforçou pra conseguir aquilo, entendeu? [...] Queremos que pra frente seja melhor" (A11). 
No que diz respeito à previsão de ações de trabalho social na política habitacional, que devem ser orientadas para o fomento à organização comunitária, a experiência do CRP-I não teve qualquer vínculo com o PTTS realizado pela prefeitura mediante contratação de empresa terceirizada. Ocorreu durante a coleta dos dados, inclusive, demonstrações de total desinteresse e até desconhecimento dos participantes a respeito do que foi realizado como trabalho social: "Teve não! [...] Na verdade eu não sei nem o que é" (A1); “Nunca participei” (A9).

O modo espontâneo como o coletivo tem conduzido as atividades influencia, entre outros aspectos, a forma intersubjetiva como os associados se percebem. Quando perguntados a respeito da atuação (coletiva) da Lambe Sal, a resposta dada foi: "A gente se vê como cidadão, né?" (A1). São sujeitos sociais, ativos, que se reconhecem como tais (Demo, 2009) por meio de vivências (compartilhadas) que valorizam uma dimensão sociocultural de identidade e se voltam à luta por direitos (Costa, 2008). O coletivo aparece, inclusive, consolidando identidades físicas, com o lugar, e de afeto, com viés sociocultural e interacional que motivam o enfrentamento a um contexto demarcado por problemas de diferentes naturezas, contornados por relações de confiança há pouco (menos de dois anos) constituídas: “É a amizade que a gente tem, um pelo outro. [...] a gente é aqui um pessoal unido. Mesmo que ser irmão. O que um precisar do outro, ajuda [...] arrecada alguma coisa [...] tem uma pessoa que tá precisando, aconteceu alguma coisa e tal [...] junta todo mundo, dá uma ajuda a ele... toda vida é assim" (A6).

O coletivo tem assumido posição de autopromoção (Demo, 2009), apropriando-se do espaço como conquista e reconhecimento social. Um ponto frequentemente percebido nas falas diz respeito ao que Demo (2009) denomina de momentos de autocrítica. São momentos que levam os informantes a refletir a respeito do papel que têm no condomínio e no campo de atuação que compete ao coletivo. Por essa razão, têm clareza da competência da associação condominial para lidar e resolver demandas da totalidade dos moradores. De outra forma, têm consciência de críticas que cercam o coletivo, a começar pela denominação, que remete à ideia de homem traído: "Se fosse outro nome da associação, com certeza teriam mais pessoas associadas" (A9).

Enquanto consideram que a denominação escolhida é motivo de críticas e impeditivo a novas adesões, não há no coletivo inclinação para alteração, pois visualizam nele uma referência para a coesão social, um símbolo, uma identidade: "Alguém sugerindo mudança de nome é uma ofensa à associação!" (A8); "Com certeza [uma mudança de nome] não vai ficar nem cinquenta, muita gente vai sair" (A1). A autocrítica ocorre não só em torno de resistências e censuras que margeiam a denominação do coletivo, bem como de eventuais prejuízos a novas adesões, mas também quanto à atuação - que, reconhecem, é limitada frente às demandas da coletividade e que, por outro lado, exigem esforços que ultrapassam as competências da associação.

Os participantes identificam que as intervenções por eles realizadas no ambiente físico, a exemplo de limpeza e conservação, correspondem na verdade a responsabilidades da gestão condominial. Além disso, reconhecem a existência de demandas no ambiente físico que precisam ser assumidas pelo poder público e que devem ser lutas do conjunto dos moradores, como é o caso da oferta de transporte público e outros serviços públicos no local. Reconhecem, assim, que se encontram, em dados momentos, extrapolando o papel que orientou a criação da associação: estreitar relações interpessoais por meio de oportunidades de lazer e integração das famílias dos sócios.

\section{CONCLUSÃO}

A gestão social é aqui reportada por movimentos emancipatórios via identidades física e de afeto entre moradores atendidas pelo conjunto de ações que a Associação Lambe Sal desenvolve em vias interacionais que extrapolam a noção exclusiva de atendimento a necessidades dos sócios e de convívio comunitário para alcançar preocupações com o exterior, especialmente com a relação condomínio-visitantes. Expressão de gestão comunitária autônoma, o coletivo informal não assumiu qualquer papel no PTTS realizado por empresa ganhadora de licitação da prefeitura. É, todavia, uma organização comunitária que mitiga conflitos e aglutina pessoas, ainda que com efeitos restritos, considerando que não é propósito do coletivo assumir funções que, de fato, pertencem à gestão condominial. O coletivo é, mesmo assim, a iniciativa que mais contribui para o sentimento e a vida comunitários, com qualidade superior à gestão condominial, realizando trabalhos em espaços comuns e eventos. Responde, inclusive, por interesses comunitários suprindo déficit financeiro da taxa condominial.

Atributos do desenvolvimento comunitário são percebidos na gestão social do CRP-I. O IBC explica a origem da associação, que surgiu de interesses pactuados em torno da vida comunitária, aproximando vizinhos para estabelecer laços de amizade e confiança. A associação mitiga deficiências de serviços e equipamentos públicos, ainda que reconhecendo limitações no 
seu papel e na sua capacidade de resolução. Via relações de proximidade e solidariedade, os sócios percebem que bem-estar coletivo é sinônimo de bem-estar individual. O coletivo não se destaca por atuação na esfera pública, em sentido amplo, considerando que não vivenciam situações, por exemplo, como negociações com agentes governamentais para resolver demandas de transporte público ou dotar o lugar de equipamentos públicos necessários, como escola.

A associação tem amplo reconhecimento internamente, e nas decisões compartilhadas os integrantes se identificam como sujeitos ativos. Proporciona coesão e mudança social, mesmo sob participação política limitada e sem interação com o poder público para reivindicar direitos. O coletivo é visto pelos sócios como alternativa de desenvolvimento comunitário, ainda que com alcance limitado. Mesmo não assumindo ações mais amplas de desenvolvimento comunitário, o coletivo tem caráter de autopromoção, na apropriação do lugar como conquista, contribuindo para a aproximação das pessoas tanto pelo trabalho voluntário de limpeza das áreas comuns quanto por eventos que, em datas comemorativas, é de acesso livre aos condôminos. As ações concorrem para a formação de identidade local e senso de pertencimento.

Apesar de os momentos da pesquisa ocorrerem no horário noturno, por sugestão dos líderes locais como medida para adequar a coleta de dados à convivência e à disponibilidade dos moradores, problemas relacionados à mobilidade foram percebidos em atrasos ocorridos para o início do diálogo e do não comparecimento de outros que, por problemas familiares ou de trabalho, não participaram. Várias foram as referências a pessoas que haviam "acabado de chegar do trabalho" e que se encontravam cansadas, ou que "estão presas no trânsito" e "tiveram imprevisto no trabalho".

Processos de gestão social vão se tornando complexos quanto mais intentam atender a interesses públicos diversos, ampliando o raio de ação e ganhando natureza difusa frente a disponibilidades limitadas de recursos. Tal risco se encontrava contido pela consciência coletiva dos sócios quanto ao papel da Lambe Sal em relação ao da associação condominial. Por essa razão, tal sucesso deve ser objeto de acompanhamento, ainda mais quando consideramos que, enquanto se encerrava esta pesquisa, os seis condomínios - cada um com trezentas unidades habitacionais - articulavam a constituição de uma associação unificada, envolvendo 1800 famílias. Resta, então, indagar: como está e que papéis assume a Lambe Sal após a constituição da associação comunitária? Que tipo de relação se estabelece entre a Lambe Sal e a associação comunitária? São questões para estudos futuros que podem ainda abordar experiências de associações e coletivos induzidos por ações de PTTS, pontuando processos internos de gestão social pela via da indução. Além disso, é oportuno tomar outros referenciais teóricos, a exemplo da psicologia ambiental, que poderá contribuir para revelar dimensões de apego ao ambiente físico e social, de afeto, mediadas pelo perfil socioeconômico e sociocultural de beneficiários de empreendimentos habitacionais de interesse social.

\section{AGRADECIMENTOS}

O presente trabalho foi realizado com apoio da Coordenação de Aperfeiçoamento de Pessoal de Nível Superior - Brasil (CAPES) Código de Financiamento 001. 


\section{REFERÊNCIAS}

Balbim, R., \& Krause, C. (2014, maio). Produção social da moradia: um olhar sobre o planejamento da Habitação de Interesse Social no Brasil. Revista Brasileira de Estudos Urbanos e Regionais, 16(1), 189-201.

Bonduki, N. (2009). Do Projeto Moradia ao programa Minha Casa, Minha Vida. Teoria e debate. Recuperado de http://www.teoriaedebate. org.br/index.php?q=materias/nacional/do-projetomoradia-aoprograma-minha-casa-minha-vida\&page $=0,0$

Caixa Econômica Federal. (2013). Caderno de orientação técnicosocial. Brasília, DF: Autor.

Camargo, B. V., \& Justo, A. M. (2016). Tutorial para uso do software IRAMUTEQ. Recuperado de http://www.iramuteq.org/documentation/ fichiers/Tutorial IRaMuTeQ em portugues_17.03.2016.pdf

Cançado, A. C., Pereira, J. R., \& Tenório, F. G. (2015). Fundamentos Teóricos da Gestão Social. Desenvolvimento Regional em debate: $D R d, 5(1), 4-19$.

Cardoso, A. L., \& Aragão, T. A. (2013). Do fim do BNH ao Programa Minha Casa Minha Vida: 25 anos da política habitacional no Brasil. In A. L. Cardoso (Org.), O Programa Minha Casa Minha Vida e seus efeitos territoriais. Rio de Janeiro, RJ: Letra Capital.

Cardoso, B. L. D. (2015). Para uma Gestão Social no Programa Minha Casa, Minha Vida: reflexões acerca da organização comunitária em empreendimentos da faixa 1 (Dissertação de Mestrado). Universidade Federal do Rio Grande do Norte, Natal, RN.

Carvalho, M. C. (1998). Participação social no Brasil hoje. Polis papers, 2, 1-30.

Costa, G. P. (2008). Cidadania e participação: impactos da política social num enfoque psicopolítico. Curitiba, PR: Juruá.

Dagnino, E. (2004a). ¿Sociedade civil, participação e cidadania: de que estamos falando? Políticas de Ciudadanía y Sociedad Civil en tempos de globalización. Caracas, Venezuela: Universidad Central de Venezuela.

Dagnino, E. (2004b). Construção democrática, neoliberalismo e participação: os dilemas da confluência perversa. Política \& Sociedade 3(5), 139-164.

Demo, P. (2009). Participação é conquista: noções de política social participativa (6a ed.). São Paulo, SP: Cortez.

Fischer, T., Melo, V. P., Carvalho, M. R., Jesus, A., Andrade, R. A., \& Waiandt, C. (2006). Perfis visíveis na gestão social do desenvolvimento. Revista de Administração Pública, 40(5), 789-808.

Fix, M., \& Arantes, P. F. (2009). Como o governo Lula pretende resolver o problema da habitação. In E. Sydow, \& M. L. Mendonça (Orgs.), Direitos Humanos no Brasil 2009: Relatório da Rede Social de Justiça e Direitos Humanos (pp. 151-160). São Paulo, SP: Rede Social de Justiça e Direitos Humanos.
Flick, U. (2009). Introdução à pesquisa qualitativa (3a ed.). São Paulo, SP: Artmed.

Grazia, G., \& Mello, I. Q. (2017). Uma avaliação do trabalho social do Programa Minha Casa Minha Vida na Região Metropolitana do Rio de Janeiro. In A. L. Cardoso, T. A. Aragão, \& S. T. Jaenisch (Orgs.), 22 anos de política habitacional no Brasil: da euforia à crise (pp. 353371). Rio de Janeiro, RJ: Letra Capital.

Habermas, J. (1997). Direito e democracia: entre facticidade e validade. Rio de Janeiro, RJ: Tempo Brasileiro.

Lei no 11.124, de 16 de junho de 2005. (2005). Dispõe sobre o Sistema Nacional de Habitação de Interesse Social - SNHIS, cria o Fundo Nacional de Habitação de Interesse Social - FNHIS e institui o Conselho Gestor do FNHIS. Brasília, DF. Recuperado de http://www.planalto. gov.br/ccivil_03/_ato2004-2006/2005/lei/l11124.htm

Nisida, V. C., Vannuchi, L. V. B., Rossi, L. G. A., Borrelli, J. F. S., \& Lopes, A. P. O. (2015, agosto). A inserção urbana dos empreendimentos do Programa Minha Casa Minha Vida na escala local: uma análise do entorno de sete conjuntos habitacionais. Revista Brasileira de Estudos Urbanos e Regionais, 17(2), 63-80.

Oliveira, V. A. R., Cançado, A. C., \& Pereira, J. R. (2010). Gestão social e esfera pública: aproximações teórico-conceituais. Cadernos EBAPE.BR, 8(4), 613-626.

Peres, M. R., Jr., \& Pereira, J. R. (2014). Abordagens Teóricas da Gestão Social: uma análise de citações exploratórias. Cadernos EBAPE.BR, 12(4), 221-236.

Presoto, L. H., \& Westphal, M. F. (2005). A participação social na atuação dos conselhos municipais de Bertioga-SP. Saúde e Sociedade, 14(1), 68-77.

Salgado, R. J. S. F., Santos, L. F., Resende, T. C., \& Souza, W. J. (2019). Cidadania deliberativa e gestão social: revisão sistemática de literatura no Brasil. Cadernos EBAPE.BR, 17(esp), 817-831.

Silva, F. R. M. (2017). Gestão do desenvolvimento territorial em empreendimentos de habitação social no Brasil (Tese de Doutorado). Universidade Federal da Bahia, Salvador, BA.

Tenório, F. G. (1998). Gestão social: uma perspectiva conceitual. Revista de Administração Pública, 32(5), 7-23.

Tenório, F. G. (2005). (Re)visitando o conceito de Gestão Social. Desenvolvimento em questão, 3(5), 101-124.

Tocqueville, A. (1998). A democracia na América. São Paulo, SP: Editora da Universidade de São Paulo.

Valadares, R. G., \& Cunha, T. A. (2018). A participação de cooperativas nas políticas públicas habitacionais no Brasil e no Uruguai. Cadernos EBAPE.BR, 16(4), 667-678. 
Suzana Melissa de Moura Mafra da Silva

ORCID: https://orcid.org/0000-0002-7691-6723

Mestra em Administração pela Universidade Federal do Rio Grande do Norte (UFRN). E-mail: suzanamelissa@gmail.com

Washington José de Souza

ORCID: https://orcid.org/0000-0001-6295-2806

Doutor em Educação pela Universidade Federal do Ceará (UFC); Professor do Departamento de Administração Pública e Gestão Social da Universidade Federal do Rio Grande do Norte (UFRN). E-mail: wsufrn@gmail.com 